\title{
Structural, Morphological and Thermal Properties of Cellulose Nanofibers from Napier fiber (Pennisetum purpureum)
}

\author{
Revati Radakisnin ${ }^{1,2}$, Mohd Shukry Abdul Majid ${ }^{1, *}$, Mohd Ridzuan Mohd Jamir ${ }^{1}$ (D), \\ Mohammad Jawaid ${ }^{3}\left(\mathbb{D}\right.$, Mohamed Thariq Hameed Sultan ${ }^{3,4,5, * \mathbb{D}}$ and Mohd Faizal Mat Tahir 6 \\ 1 Faculty of Mechanical Engineering Technology, Universiti Malaysia Perlis (UniMAP), Pauh Putra Campus, \\ Arau, Perlis 02600, Malaysia; revark_1990@yahoo.com (R.R.); ridzuanjamir@unimap.edu.my (M.R.M.J.) \\ 2 Faculty of Electronic Engineering Technology, Universiti Malaysia Perlis (UniMAP), Pauh Putra Campus, \\ Arau, Perlis 02600, Malaysia \\ 3 Laboratory of Biocomposite Technology, Institute of Tropical Forestry and Forest Products (INTROP), \\ Universiti Putra Malaysia, Serdang, Selangor 43400, Malaysia; jawaid@upm.edu.my \\ 4 Department of Aerospace Engineering, Faculty of Engineering, Universiti Putra Malaysia, Serdang, \\ Selangor Darul Ehsan 43400, Malaysia \\ 5 Aerospace Malaysia Innovation Centre (944751-A), Prime Minister's Department, MIGHT Partnership Hub, \\ Jalan Impact, Cyberjaya, Selangor Darul Ehsan 63000, Malaysia \\ 6 Center for Integrated Design of Advanced Mechanical Systems (PRISMA), Faculty of Engineering and Built \\ Environment, Universiti Kebangsaan Malaysia, Bandar Baru Bangi, Selangor 43600, Malaysia; \\ mfaizalmt@ukm.edu.my \\ * Correspondence: shukry@unimap.edu.my (M.S.A.M.); thariq@upm.edu.my (M.T.H.S.)
}

Received: 6 August 2020; Accepted: 10 September 2020; Published: 17 September 2020

check for updates

\begin{abstract}
The purpose of the study is to investigate the utilisation of Napier fiber (Pennisetum purpureum) as a source for the fabrication of cellulose nanofibers (CNF). In this study, cellulose nanofibers (CNF) from Napier fiber were isolated via ball-milling assisted by acid hydrolysis. Acid hydrolysis with different molarities (1.0, 3.8 and $5.6 \mathrm{M}$ ) was performed efficiently facilitate cellulose fiber size reduction. The resulting CNFs were characterised through Fourier-transform infrared spectroscopy (FTIR), X-ray diffraction (XRD), thermogravimetric analysis (TGA), particle size analyser (PSA), field-emission scanning electron microscopy (FESEM), atomic force microscopy (AFM), and transmission electron microscopy (TEM). The FTIR results demonstrated that there were no obvious changes observed between the spectra of the CNFs with different molarities of acid hydrolysis. With $5.6 \mathrm{M}$ acid hydrolysis, the XRD analysis displayed the highest degree of CNF crystallinity at $70.67 \%$. In a thermal analysis by TGA and DTG, cellulose nanofiber with $5.6 \mathrm{M}$ acid hydrolysis tended to produce cellulose nanofibers with higher thermal stability. As evidenced by the structural morphologies, a fibrous network nanostructure was obtained under TEM and AFM analysis, while a compact structure was observed under FESEM analysis. In conclusion, the isolated CNFs from Napier-derived cellulose are expected to yield potential to be used as a suitable source for nanocomposite production in various applications, including pharmaceutical, food packaging and biomedical fields.
\end{abstract}

Keywords: Napier fiber; cellulose nanofiber; crystallinity; morphology properties; thermal properties

\section{Introduction}

The fibers of Napier grass, also commonly known as Pennisetum purpureum (PP), are made up of $46 \%$ cellulose, $34 \%$ hemicellulose, and $20 \%$ lignin [1]. In addition, it requires only a minimal supply 
of nutrients for growth. In order to eliminate impurities and non-cellulosic material, an alkaline treatment was implemented in most studies, using sodium hydroxide $(\mathrm{NaOH})(4-20 \%)$ with $1-5 \mathrm{~h}$ of continuous stirring. The treated fibers were then washed with distilled water until the $\mathrm{pH}$ was neutralised and then dried in an oven overnight at $50{ }^{\circ} \mathrm{C}$ [2]. Eliana et al. reported that Napier fibers with alkaline pre-treatment yielded the highest percentages of lowering sugars and ethanol [3]. It was reported that the delignification of Napier grass was carried out by alkaline treatment with different concentration from 0.5 to $10.5 \mathrm{wt}$. $\%$, thus resulting in $80.59 \%$ cellulose and removal of $93.78 \%$ lignin [4]. Ridzuan et al. recommended Napier fiber as a potential reinforcement material in polymer composites [5]. Devin and Samir also recommended cellulosic fibers from Napier grass can be used as supporting material for biofuel productions owing to the high moisture content of the cellulose [6]. According to the previous studies, alkaline pre-treatment is a preferred method for hemicellulose and lignin removal; thus, cellulose retrieval from this method is promising. Alkaline post-treatment is also proposed in this study to eliminate any remaining hemicellulose and lignin further.

Recently, the development of nanocellulose from cellulose source as a preferred reinforcement for nanocomposites has generated significant research interest on the utilisation of natural fibers owing to their outstanding mechanical properties, sustainability, affordability, low environmental impact, and relatively good specific features. There are several literature reviews on the expansion of nanocellulose from cellulose source, via various methods. V. K. Baheti et al. had conducted dry and wet ball milling of CNF from jute fiber wastes, which resulted in nanoparticles sized below $500 \mathrm{~nm}$ with a small amount of contamination imported from milling media [7]. Morais et al. studied on $\mathrm{CNF}$ from different types of cotton fibers using acid hydrolysis with $6.5 \mathrm{M}$ of sulphuric acid at $45^{\circ} \mathrm{C}$. They concluded that extraction yield, sulfonation efficiency, and thermal stability varies according to the type of cotton fibers [8]. Zhijun et al. obtained CNF from bamboo fiber from a combination of mechanical treatment, enzyme activation, carboxymethylation, and ultrasonic homogenisation [9]. They found that extraction yield, surface charge and carboxymethylation reaction was enhanced through the existing preparation procedures. Based on these reviews and the related studies regarding the nanofibers from cellulose, it can be concluded that preparation and isolation plays a crucial part in producing a good cellulose nanofiber with enhanced structural and mechanical properties.

Nanocellulose is described as a natural nanomaterial that is either a product of or is extracted from native cellulose sources, such as plants [10]. The obtained cellulose from plants can be further reduced into smaller cellulose fragments that are either micro-sized or nano-sized. Nanocellulose, with its nano-sized diameter, has many advantages such as a high surface area, good strength and stiffness, excellent chemical reactivity, and being low in density [11]. Recently, they have been widely used as cellulose nanofibers (CNF), or cellulose nanocrystals (CNC), attracted positive attention in many industries such as the automotive [12], biomedical [13-15], and pharmaceutical industries [10], and have also found use as reinforcements in polymeric nanocomposites [16,17]. From previous studies, nanocellulose fibers have been successfully extracted from cellulose sourced from softwood [18], cotton [8,19,20], roselle [21], jute fiber [22], banana peel [23,24], and bamboo [25]. Nevertheless, it is crucial to acknowledge that cellulose characteristics, such as the structural morphology, degree of crystallinity, degree of polymerisation, and size, depend upon the source from which the cellulose was extracted and not just on the extraction method employed [26,27].

$\mathrm{CNF}$, also recognised as cellulose nanofibril or nanofibrillated cellulose, is the entangled, long, and flexible nanocellulose that can be produced from cellulose fibers that undergo mechanical processes in which both shear and impact forces are used [28]. The key feature is the size of the cellulose nanofiber, which is typically less than $100 \mathrm{~nm}$ in diameter and several micrometres in length [2]. The most commonly used mechanical techniques used to produce CNFs include microfluidisation, ultrasonication, high-pressure homogenisation, ball milling, and micro-grinding [18,29-31]. However, high-energy consumption is a major drawback of the mechanical processes used for the production of CNFs, where the production of fine particles sizes down to the range of nanometers was transformed by this high-energy ball milling by increasing rotational speed up to $1100 \mathrm{rpm}$ for a couple of hours [32-34]. 
To overcome this shortcoming, the mechanical processes are combined with chemical pre-treatment to reduce the energy consumption, since pre-treated cellulose fibers are easily fibrillated and also prevent clogging $[35,36]$.

Recently, various researches have illustrated the synthesis and isolation process of cellulose nanofibers by combining both chemical and mechanical treatments effectively. Leticia et al. had researched isolation of CNFs from cassava root baggase and peelings using 30,40, and 50\% of sulfuric acid, and the hydrolyzed suspensions were further homogenized to reduce the size and to disperse the CNFs using ultrasound. They conclude that the isolation of CNFs is inexpensive and nanofibers with excellent properties can be obtained [37]. The extraction of CNFs from pineapple leaf fibers (PALF) had been studied by Lakshmipriya et al. where the fibers were subjected to acid hydrolysis with $50 \%$ of sulfuric acid, and further ball-milled the suspension for 1.5 and $3 \mathrm{~h}$. They found that the extraction process is environmentally sustainable and economical for the fabrication of good-quality CNF [38]. Lastly, Kittiya et al. had investigated the effect of sulfuric acid concentration on sugarcane bagasse fibers. The cellulose was ball-milled for $12 \mathrm{~h}$ with acid hydrolysis where the concentrations of sulfuric acid are 0,20 , and $40 \%$. The researcher illustrated that the extracted CNFs has greater absorption than raw cellulose, whereas the crystallinity of the isolated CNFs was higher than untreated cellulose [39].

From the literature review conducted, it is evident that there are fewer reported studies on the optimisation of cellulose extraction from Napier fiber as a resource for developing CNFs. The objective of this research is to isolate and prepare cellulose nanofibers from Napier fiber by combining mechanical processing with acid hydrolysis and ultrasonication. The structural morphology, thermal stability and crystallinity of the isolated CNFs were then characterised. Hence, this study is to provide crucial information in preparing a future study on CNF from Napier fiber to look its appropriateness in synthesising nanocomposites for application advancements.

\section{Materials and Experimental Methods}

\subsection{Materials}

Raw Napier grass was obtained from a nearby plantation at Bukit Kayu Hitam, Kedah; northern peninsular Malaysia. Sulfuric acid $\left(\mathrm{H}_{2} \mathrm{SO}_{4}\right)$ (purity $\geq 98 \mathrm{wt} \%, \mathrm{Mm}=98 \mathrm{~g} / \mathrm{mol}$ ), and sodium hydroxide $(\mathrm{NaOH})$ were obtained from Fisher Scientific. All other chemicals used in this work were of reagent grade and purchased from local suppliers. De-ionised water was used throughout the experiments.

\subsection{Extraction and Preparation of Napier Fibers}

Water retting was employed in this study to remove the Napier fibers from the stem internodes [5]. The stems were at first cleaned and crushed into small pieces using a mallet before being soaked in a tank filled with water for 4 to 6 weeks to ease the separation process. The Napier fibers were manually extracted from the bast and cleaned with distilled water. The extracted fibers were sun-dried to remove the excess moisture content, which may exist within the fibers. Subsequently, the dried fibers were ground and sieved to convert the Napier fibers into fine particles $(<63 \mu \mathrm{m})$.

\subsection{Preparation of Cellulose Nanofibers from Napier Fibers (CNF-PP)}

The ground fibers were further treated with $12 \% \mathrm{NaOH}$ at $25^{\circ} \mathrm{C}$ with an immersion time of $120 \mathrm{~min}$. A liquor ratio of 20:1 was used in this experiment to eliminate the hemicellulose, lignin, and impurities from the fibers. Subsequently, the treated fibers were cleaned with distilled water and air-dried at $25^{\circ} \mathrm{C}$. The obtained fibers that maximally reduced hemicellulose and lignin contents were acid hydrolysed by treating $10 \mathrm{~g}$ cellulose with $400 \mathrm{~mL}$ of $1.0 \mathrm{M}, 3.8 \mathrm{M}$ and $5.6 \mathrm{M} \mathrm{H}_{2} \mathrm{SO}_{4}$, respectively, at $80{ }^{\circ} \mathrm{C}$ for $60 \mathrm{~min}$ under continuous mechanical stirring. The resulting mixture after each acid hydrolysis was repeatedly centrifuged at $3000 \mathrm{rpm}$ for $25 \mathrm{~min}$. The suspension was further neutralised for three days using a dialysis membrane (30 mm diameter, MWCO 12,000-14,000, SERVAPOR, SERVA Electrophoresis 
$\mathrm{GmbH}$, Heidelberg, Germany) with distilled water to reach a neutral $\mathrm{pH}$. Post-treatment of Napier fibers was then conducted to eliminate the remaining impurities from the fibers. The fibers were treated with a $4 \% \mathrm{NaOH}$ solution at $80^{\circ} \mathrm{C}$ for a further $60 \mathrm{~min}$ with continuous stirring. The suspension was centrifuged and washed using distilled water until the $\mathrm{pH}$ of the suspension became neutral.

After the chemical treatment, milling of the Napier fibers was carried out by a planetary ball milling machine (Bench-Top Planetary Automatic Ball Mill, MSK-SFM-1, MTI, Richmond, VA, Canada) in a zirconia bowl using zirconia balls with a diameter of $15 \mathrm{~mm}$ for $180 \mathrm{~min}$ of wet milling in de-ionised water. The ball to material ratio (BMR) of the container loaded with fibers was 10:1, and the speed of rotation of the container was set at $840 \mathrm{rpm}$. The resulting suspension was further sonicated for $15 \mathrm{~min}$ in an ultrasonicator (Branson Digital Signifier, Emerson, Danbury, CT, USA) at an amplitude of $40 \%$ with $8 \mathrm{~s}$ of pulse on, and $4 \mathrm{~s}$ of pulse off. Ultrasonication was done in an ice-bath to prevent heat-up where desulfation can occur due to the presence of sulfate groups on the fibers. Finally, the suspension was freeze-dried and stored for further characterisation and use as reinforcement fillers in biocomposites. A summary of the selected processing parameters for the synthesis of CNFs from Napier fibers is given in Table 1.

Table 1. Selected processing parameters for the synthesis of cellulose nanofibers (CNFs) from Napier fibers.

\begin{tabular}{|c|c|c|c|c|c|c|}
\hline \multirow{2}{*}{ Sample } & \multirow{2}{*}{$\begin{array}{c}\text { Alkaline } \\
\text { Pre-Treatment }\end{array}$} & \multirow{2}{*}{$\begin{array}{l}\text { Acid Hydrolysis } \\
\text { Molarity }\end{array}$} & \multirow{2}{*}{$\begin{array}{c}\text { Alkaline } \\
\text { Post-Treatment }\end{array}$} & \multicolumn{3}{|c|}{ Ball Milling } \\
\hline & & & & Time (Minutes) & Speed (rpm) & Ball Size $(\mathrm{mm})$ \\
\hline CNF-PP $_{1.0 \mathrm{M}}$ & $12 \%$ & $1.0 \mathrm{M}$ & $4 \%$ & 180 & 840 & 15 \\
\hline $\mathrm{CNF}^{-P_{3.8 \mathrm{M}}}$ & $12 \%$ & $3.8 \mathrm{M}$ & $4 \%$ & 180 & 840 & 15 \\
\hline $\mathrm{CNF} \mathrm{PP}_{5.6 \mathrm{M}}$ & $12 \%$ & $5.6 \mathrm{M}$ & $4 \%$ & 180 & 840 & 15 \\
\hline
\end{tabular}

\subsection{Characterisation}

\subsubsection{Fourier Transform Infrared Spectroscopy (FTIR)}

Infrared spectra were used to identify the chemical structure of the lignocellulosic elements present in the samples. Fiber spectra were characterised using a Perkin Elmer Spectrum Version 10.5.2 spectrophotometer with a total of 42 scans in the range of $4000-600 \mathrm{~cm}^{-1}$. A resolution of $4 \mathrm{~cm}^{-1}$ was used in this work.

\subsubsection{X-Ray Diffraction (XRD)}

XRD was used to analyse the phase composition of the samples using a D2 Phase Bruker diffractometer with $\mathrm{Cu}-\mathrm{K} \alpha$ radiation at $30 \mathrm{~mA}$ and $40 \mathrm{kV}$. Scattered radiation was recorded in the interval $10^{\circ} \leq 2 \theta \leq 80^{\circ}$ at a scan speed of $4^{\circ} / \mathrm{min}$ with a step time of $0.24 \mathrm{~s}$ and a step size of $0.02^{\circ}$ 20. The crystallinity index (CrI) of the cellulose, CrI, was calculated using the empirical method [40], as illustrated in Equation (1)

$$
\operatorname{CrI}(\%)=\frac{\mathrm{I}_{200}-\mathrm{I}_{\mathrm{am}}}{\mathrm{I}_{200}} \times 100
$$

where $\mathrm{I}_{200}$ represents the crystalline peak corresponding to the intensity at approximately $22.4^{\circ}$, and $\mathrm{I}_{\mathrm{am}}$ is the amorphous peak corresponding to the intensity at approximately $18.32^{\circ}$.

\subsubsection{Particle Size Measurements}

The average hydrodynamic particle size of the fabricated CNFs in aqueous suspension was determined using a particle size analyser (PSA) (Malvern Instruments, Nano Z.S., Malvern Panalytical Ltd., Malvern, UK). The CNF particles were analysed in the range from 0.6 to $6000 \mathrm{~nm}$ under the following conditions: a temperature of $25^{\circ} \mathrm{C}$, viscosity of $1,2000 \mathrm{mPas}$, and scattering angle fixed at $90^{\circ}$. The sonicated CNF suspensions were all evaluated in triplicate. 


\subsubsection{Thermogravimetric Analysis (TGA)}

Thermal stability was measured using a thermogravimetric analyser (Shimadzu DTG 60H, Kyoto, Japan). Samples weighing $10 \mathrm{mg}$ were placed in an alumina crucible and evaluated by increasing the temperature constantly from 30 to $950^{\circ} \mathrm{C}$. All measurements were made under the flow of the dynamic nitrogen gas carrier with a flow rate of $20 \mathrm{~mL} / \mathrm{min}$. The loss of weight was obtained from the TGA curve of a plot of weight loss $(\%)$ versus temperature $\left({ }^{\circ} \mathrm{C}\right)$.

\subsubsection{Field Emission Scanning Electron Microscopy (FESEM)}

The surface morphology of the CNFs was investigated using FESEM, performed on a ZEISS MERLIN, Jena, Germany field emission scanning electron microscope at an acceleration voltage of $20 \mathrm{kV}$. The freeze-dried CNF samples were cut into a thin layer and mounted individually onto a sample holder. In order to avoid unwanted charging, the surface of each of the prepared samples was further sputtered with a thin layer of gold before FESEM was initiated. All measurements of the CNFs from FESEM images were obtained using the Smart Tiff software.

\subsubsection{Atomic Force Microscope (AFM)}

The structural morphology and topography of the CNFs from Napier fibers were analysed by AFM. The samples were examined in a Park Systems NX-10 microscope, Suwon, Korea. A droplet of the CNF suspension was deposited on a glass slide, allowed to dry at $25{ }^{\circ} \mathrm{C}$ overnight, and then analysed by AFM. The AFM experiments were conducted in the tapping mode, at $25^{\circ} \mathrm{C}$. The scan was carried out at a rate of $1 \mathrm{~Hz}$, with an image resolution of $0.015 \mathrm{~nm}$, attached to a silicon cantilever spring constant of between 25 and $50 \mathrm{~N} \mathrm{~m}^{-1}$, followed by a resonance frequency up to $10.5 \mathrm{kHz}$. The width of the CNFs was analysed from the AFM images using XEI software.

\subsubsection{Transmission Electron Microscopy (TEM)}

The TEM measurements were performed with an FEI Talos L120C microscope, Thermo Fisher Scientific, Oregon, OR, USA. CNF from Napier fibers was further diluted using ethanol before a drop of the diluted Napier nanofiber suspension was deposited onto a thin carbon-coated copper grid. The prepared samples were allowed to dry at $25^{\circ} \mathrm{C}$ and observed and analysed through TEM at an acceleration voltage of $80 \mathrm{kV}$. The average diameter of the CNFs was calculated from the obtained TEM images using Image J software.

\section{Results and Discussions}

\subsection{Morphology of CNFs from Napier}

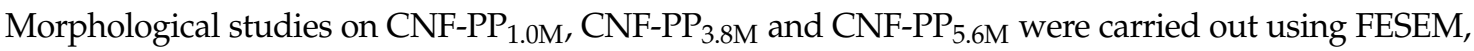
TEM, and AFM, and the obtained results are shown in Figure 1. Table 2 displays the morphological characterisations, where the diameters of $\mathrm{CNF}^{-P_{1.0 \mathrm{M}}}, \mathrm{CNF} \mathrm{PP}_{3.8 \mathrm{M}}$ and $\mathrm{CNF}^{-\mathrm{PP}_{5.6 \mathrm{M}}}$ are recorded. Figure 1a-c shows the FESEM micrographs of $\mathrm{CNF}^{-\mathrm{PP}_{1.0 \mathrm{M}}}, \mathrm{CNF}^{\mathrm{P}} \mathrm{PP}_{3.8 \mathrm{M}}$ and $\mathrm{CNF}-\mathrm{PP}_{5.6 \mathrm{M}}$, respectively, displaying their homogeneity and nanometric dimensions. The diameters of all three samples were computed by analysing the image using the processing software, Image J. The smallest and biggest diameters of $\mathrm{CNF}^{-P_{1.0 \mathrm{M}}}, \mathrm{CNF}^{\mathrm{P} P P_{3.8 \mathrm{M}}}$ and $\mathrm{CNF}^{-P_{5} .6 \mathrm{M}}$ were 49.93 and $167.6 \mathrm{~nm}, 25.46$ and $34.67 \mathrm{~nm}$, then 16.10 and $34.95 \mathrm{~nm}$, respectively. Figure 1a-c shows the structure of the nanofibers after the acid hydrolysis and ball milling treatments. It can be seen that both treatments assist the separation of the bundle of fibers into individual fibers and fibrous network, thus leading to a significant reduction in their diameter size. The nanofibers of $\mathrm{CNF}^{-P_{1.0 \mathrm{M}}}, \mathrm{CNF} \mathrm{PP}_{3.8 \mathrm{M}}$ and $\mathrm{CNF}-\mathrm{PP}_{5.6 \mathrm{M}}$ were visible in the freeze-dried samples. Nano-fragments may tend to agglomerate with nanofibers by an interfacial hydrogen bonding. 


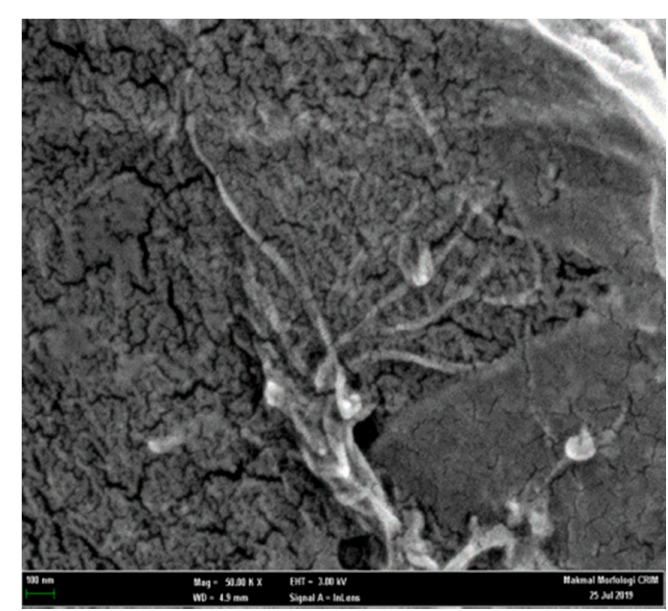

(a)

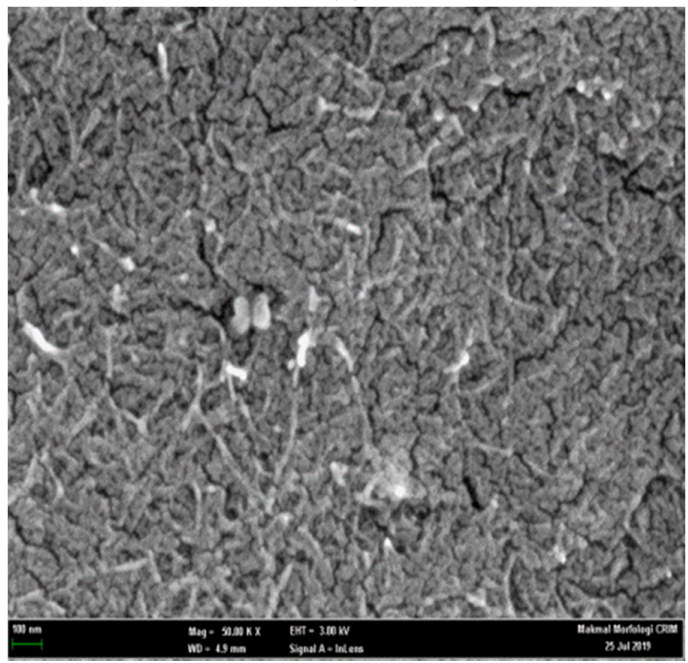

(c)

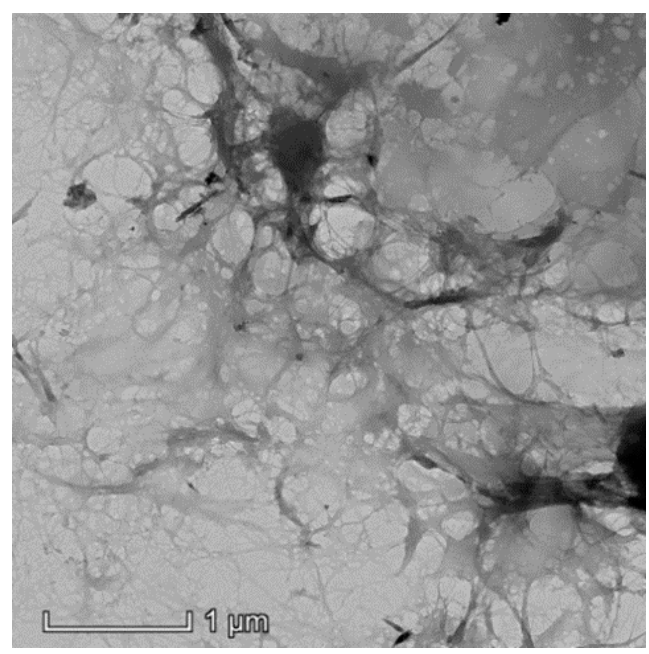

(e)

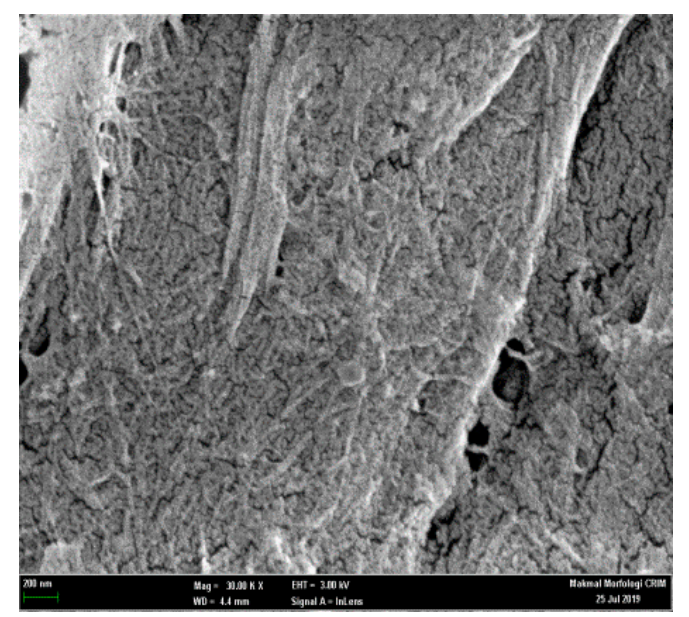

(b)

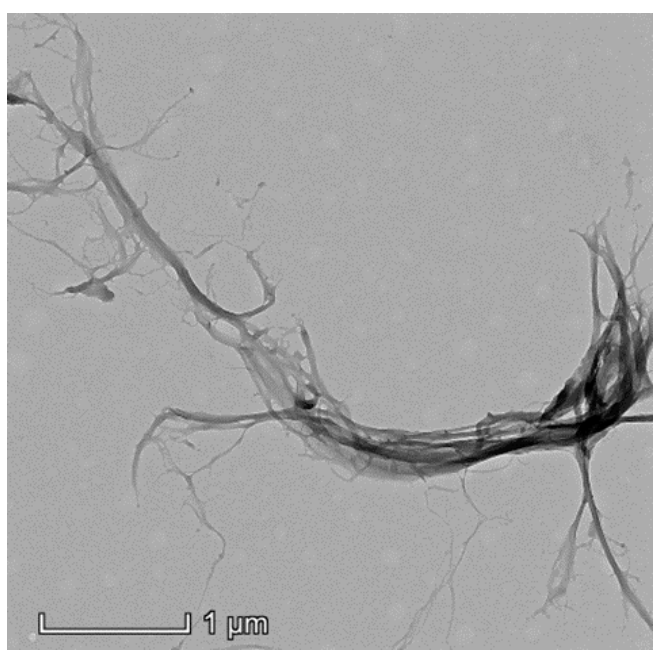

(d)

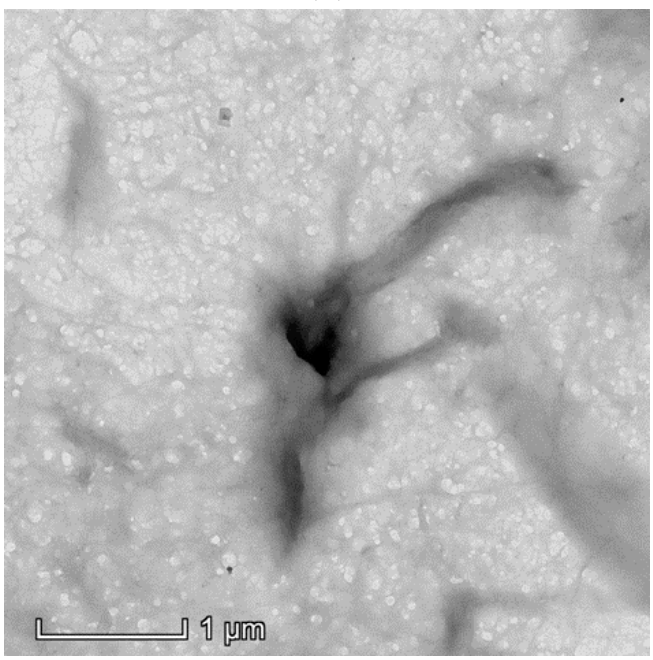

(f)

Figure 1. Cont. 


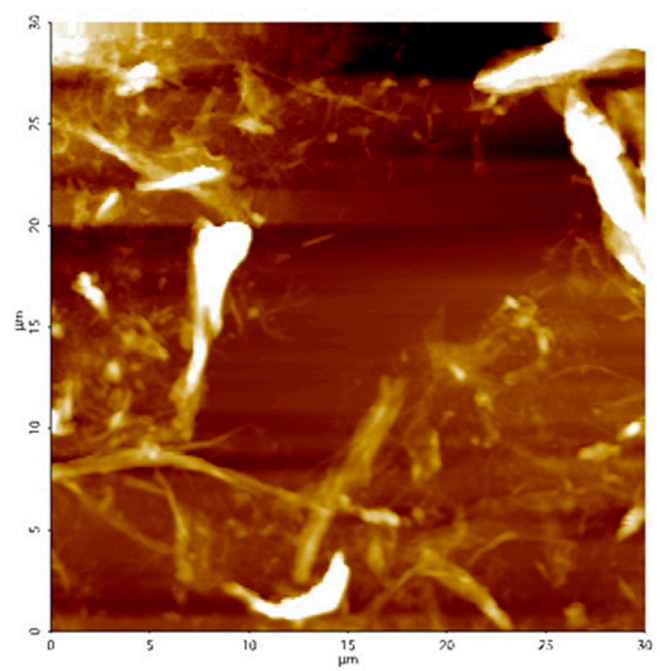

(g)

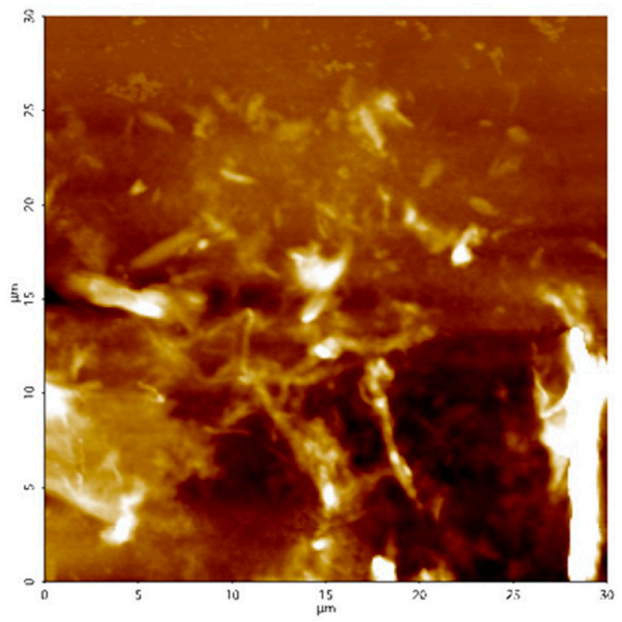

(i)

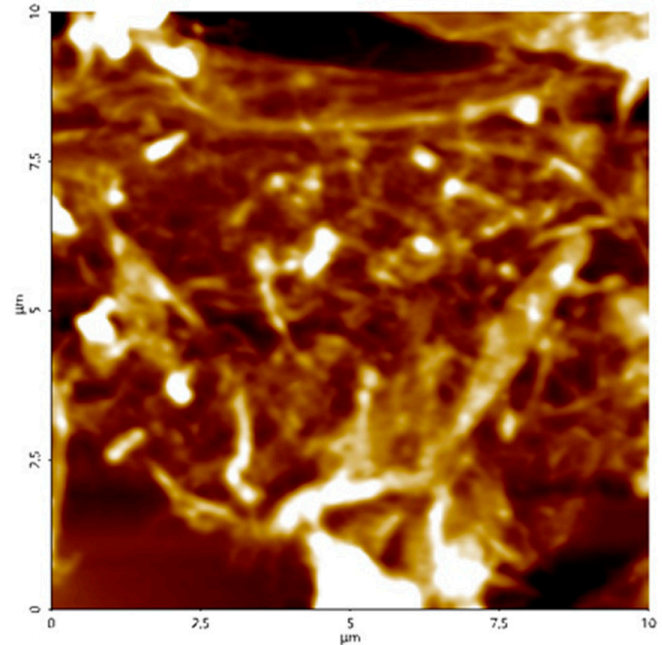

(h)

Figure 1. Field-emission scanning electron microscopy (FESEM) (a-c), transmission electron microscopy (TEM) (d-f), and atomic force microscopy (AFM) $(\mathbf{g}-\mathbf{i})$ results for CNF-PP $1.0 \mathrm{M}(\mathbf{a}, \mathbf{d}, \mathbf{g}), \mathrm{CNF} \mathrm{PP}_{3.8 \mathrm{M}}$ $(\mathbf{b}, \mathbf{e}, \mathbf{h})$ and $\mathrm{CNF}^{-P P_{5.6 \mathrm{M}}}(\mathbf{c}, \mathbf{f}, \mathbf{i})$.

Table 2. Diameters of $\mathrm{CNF}^{-P_{1.0 \mathrm{M}}}, \mathrm{CNF} \mathrm{PP}_{3.8 \mathrm{M}}$, and $\mathrm{CNF}-\mathrm{PP}_{5.6 \mathrm{M}}$ analysed by FESEM, TEM, and AFM microscopy.

\begin{tabular}{|c|c|c|c|}
\hline Samples & $\begin{array}{c}\text { FESEM (Diameter Size Range) } \\
(\mathbf{n m})\end{array}$ & $\begin{array}{c}\text { TEM (Diameter Size Range) } \\
(\mathrm{nm})\end{array}$ & $\begin{array}{c}\text { AFM (Diameter Size Range) } \\
(\mathrm{nm})\end{array}$ \\
\hline $\mathrm{CNF} \mathrm{PP}_{1.0 \mathrm{M}}$ & $49.93-167.60$ & $5.04-90.67$ & $26.44-192.50$ \\
\hline $\mathrm{CNF} \mathrm{PP}_{3.8 \mathrm{M}}$ & $25.46-34.67$ & $4.40-22.62$ & $19.64-53.28$ \\
\hline $\mathrm{CNF} \mathrm{PP}_{5.6 \mathrm{M}}$ & $16.10-34.95$ & $5.67-13.70$ & $10.50-38.74$ \\
\hline
\end{tabular}

Figure $1 \mathrm{~d}-\mathrm{f}$ shows TEM image of $\mathrm{CNF}^{-P_{1.0 \mathrm{M}}}, \mathrm{CNF}-\mathrm{PP}_{3.8 \mathrm{M}}$ and $\mathrm{CNF} \mathrm{PP}_{5.6 \mathrm{M}}$. Based on the TEM analysis, $\mathrm{CNF}_{-\mathrm{PP}} 1.0 \mathrm{M}$ displayed an individuated, long, and fine nanofiber structure instead of a fibrous network structure; whereas for $\mathrm{CNF}_{-P_{3} .8 \mathrm{M}}$ and $\mathrm{CNF}-\mathrm{PP}_{5.6 \mathrm{M}}$, a network-like fiber structure was observed. The ability to form a network of fibers is an essential criterion for nanofibers to develop into an effective reinforcement material when applied to biocomposites. Moreover, the $\mathrm{CNF}_{\mathrm{PP}} \mathrm{P}_{1.0 \mathrm{M}}$ contained diameter sizes ranging from 5.04 to $90.67 \mathrm{~nm}$ compared to those of CNF-PP $3.8 \mathrm{M}$ and $\mathrm{CNF}_{-\mathrm{PP}} \mathrm{5}_{6 \mathrm{M}}$, which had the range $4.40-22.62$ and $5.67-13.70 \mathrm{~nm}$, respectively (Table 2). It is also important to note that the lengths of the obtained CNFs were estimated to be in the micrometric scale. 
The reduction in the diameter of $\mathrm{CNF}_{-P_{1.0 \mathrm{M}}}, \mathrm{CNF} \mathrm{PP}_{3.8 \mathrm{M}}$ and $\mathrm{CNF}-\mathrm{PP}_{5.6 \mathrm{M}}$ were caused by the removal of lignin, hemicellulose, and the non-cellulosic parts of Napier, through the alkaline treatments (preand post-), acid hydrolysis and ball milling treatments. The morphology results of the CNF-PP $1.0 \mathrm{M}$, $\mathrm{CNF}_{-P_{3} .8 \mathrm{M}}$ and $\mathrm{CNF} \mathrm{PP}_{5.6 \mathrm{M}}$ samples in this study correlated well with the dimensions of the CNFs from kenaf (1-40 nm) [41], banana peel (20-50 nm) [24], cotton (20-80 nm) [19], and pineapple leaf fibers $(20-50 \mathrm{~nm})$ [38].

The CNFs obtained after acid hydrolysis and ball milling were analysed by AFM to determine their structure and diameter. The AFM image in Figure $1 \mathrm{~g}$ displays the structural morphology of $\mathrm{CNF}_{\mathrm{N}} \mathrm{PP}_{1.0 \mathrm{M}}$. It can be observed that the cellulose is nano-sized with a diameter ranging from 26.44 to $192.50 \mathrm{~nm}$.

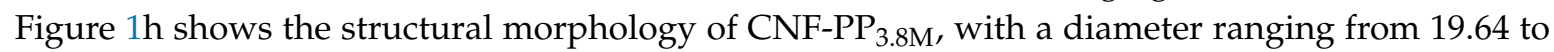
$53.28 \mathrm{~nm}$, whereas Figure $1 \mathrm{i}$ displayed a diameter ranging from 10.50 to $38.74 \mathrm{~nm}$. CNF-PP $3.8 \mathrm{M}$ and $\mathrm{CNF}_{-} \mathrm{PP}_{5.6 \mathrm{M}}$ presented more densely packed fibrous networks of cellulose nanofiber than $\mathrm{CNF}^{-P P_{1.0 \mathrm{M}}}$ (Figure $1 \mathrm{~b}, \mathrm{c}$ ), but both $\mathrm{CNF}_{\mathrm{PP}} \mathrm{P}_{1.0 \mathrm{M}}$ and $\mathrm{CNF}^{-\mathrm{PP}_{3.8 \mathrm{M}}}$ displayed network-like structures of $\mathrm{CNFs}$ which

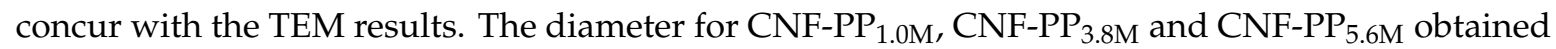
from AFM were larger than the diameter ranges from FESEM and TEM analysis. This is similar to the AFM results obtained for the isolation of CNFs from softwood pulp using TEMPO techniques [18]. A similar outcome was observed by Niu et al., where the extraction of CNC from microcrystalline cellulose using acid hydrolysis assisted by ultrasonication degraded the impurities and decreased the diameter of the CNC, breaking them down into nano-sized particles [42].

By comparing the structural morphology results obtained from FESEM, TEM, and AFM, it can be concluded that of all the microscopic analyses, TEM presented the clearest insight into CNF morphology, with a diameter size between 5.04 and $90.67 \mathrm{~nm}$ for $\mathrm{CNF}_{-\mathrm{PP}} \mathrm{PMM}_{1.0 \mathrm{M}}, 4.40$ and $22.62 \mathrm{~nm}$ for $\mathrm{CNF}^{-P_{3}} \mathrm{P}_{3.8 \mathrm{M}}$, and 5.67 and $13.70 \mathrm{~nm}$ for $\mathrm{CNF}_{-P_{5}}$. Ad . Aditionally, all three samples displayed a fibrous network structure; hence, the structural morphology showed an increase in specific surface area compared to extracted Napier fibers. On the other hand, it was noticeable that the diameter measured using AFM was slightly larger than that from the FESEM and TEM analyses. This could be due to the broadening effect in AFM, where the broadening of the sample width depends on its physical properties and position concerning the tip radius. Another crucial aspect that might affect AFM is the placement of the nanofibers on the holder that may lead to random measurements due to the irregular shape of the nanofibers [43]. Thus, the combination of acid hydrolysis and ball milling further proved that when the impurities covering the CNFs were effectively removed, a reduction from micro-sized raw cellulose, composed of bundles of fibers, into nano-sized CNFs occurs.

\subsection{Particle Size Measurement}

Particle size analysis (PSA) is a method used to obtain the particle size of CNFs in suspension that undergoes Brownian motion generated by thermally induced collisions between the CNF particles and solvent particles. The measured particle size, often called a hydrodynamic diameter, which indicates the way that the CNF particle diffuses within a fluid. It is essential to understand that PSA is based on the Stokes-Einstein equation, where the measurements refer to spherical particles and the orientation of the CNFs in suspension profoundly influences the particle size values obtained [44]. The size distribution of $\mathrm{CNF}^{-P} \mathrm{P}_{1.0 \mathrm{M}}, \mathrm{CNF}^{-P P_{3.8 \mathrm{M}}}$ and $\mathrm{CNF}-\mathrm{PP}_{5.6 \mathrm{M}}$, as measured by particle size analysis, is shown in Figure 2a,b.

Figure $2 \mathrm{a}$ shows the intensity weighted distribution of the $\mathrm{CNF}_{\mathrm{PP}} \mathrm{P}_{1.0 \mathrm{M}}, \mathrm{CNF} \mathrm{PP}_{3.8 \mathrm{M}}$ and $\mathrm{CNF} \mathrm{PP}_{5.6 \mathrm{M}}$ samples as detected by laser diffraction. $\mathrm{CNF} \mathrm{PP}_{1.0 \mathrm{M}}$ showed a single peak with a value of approximately $525 \mathrm{~nm}$. CNF-PP $3.8 \mathrm{M}$ displayed two peaks, minor peak with a mean value of $3 \mathrm{~nm}$ and maximum intensity of approximately $8 \%$ and a major peak with a mean value of $89 \mathrm{~nm}$ and maximum intensity of approximately $92 \%$ whereas for $\mathrm{CNF}^{-P_{5}} \mathrm{P}_{5.6}$, three different peaks were observed. The first with an average size of $1 \mathrm{~nm}$ and an intensity of approximately $6 \%$, the second with a mean value of $344 \mathrm{~nm}$ and maximum intensity of approximately $81 \%$, and the third with a mean value of $3800 \mathrm{~nm}$ and maximum intensity of approximately $11 \%$. Based on the results, $\mathrm{CNF}_{\mathrm{PP}}$.6M possesses 
larger particle sizes, indicating that particles aggregated in suspension more rapidly than CNF-PP $1.0 \mathrm{M}$ and CNF-PP ${ }_{3.8 \mathrm{M}}$ particles. This is the case for particles that possess high hydrophobic characteristics, i.e., samples containing less hydroxyl groups tend to aggregate easily [45].

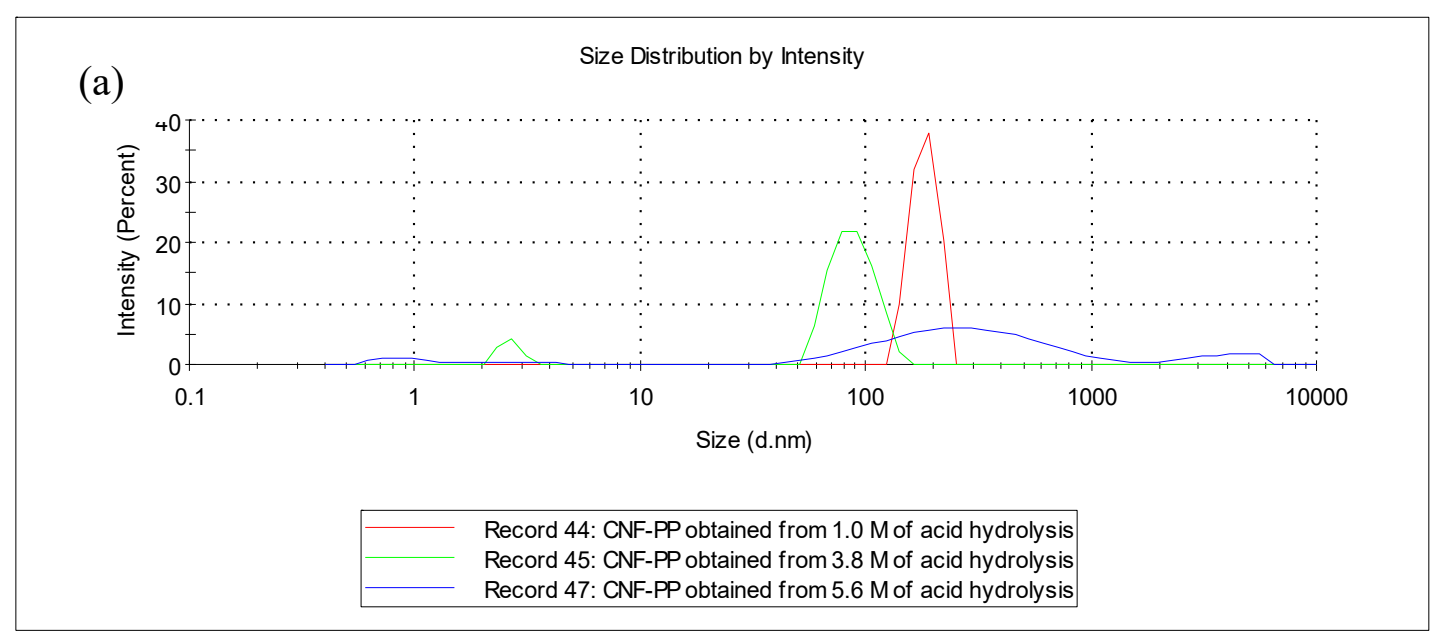

(b)

Size Distribution by Volume

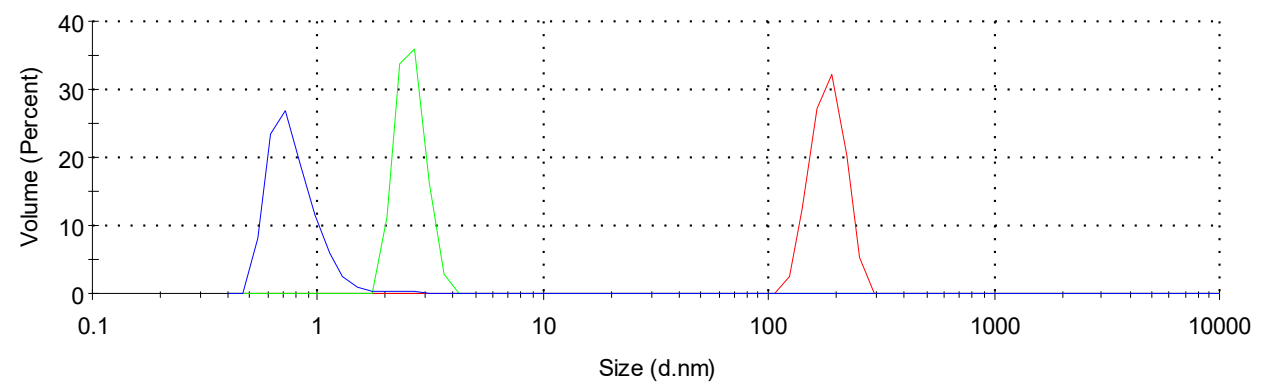

Record 44: CNF-PP obtained from 1.0 M of acid hydrolysis

Figure 2. Particle size distribution by particle size analysis (PSA) (a) intensity-weighted distribution and (b) volume-weighted distribution of $\mathrm{CNF}^{-P_{1.0 \mathrm{M}}}, \mathrm{CNF} \mathrm{PP}_{3.8 \mathrm{M}}$ and $\mathrm{CNF}-\mathrm{PP}_{5.6 \mathrm{M}}$.

Concerning the volume-weighted distribution (Figure $2 b$ ), the majority of the particles were in an equivalent volume range from 0.5 to $5 \mathrm{~nm}$ for $\mathrm{CNF}^{-P_{5.6 \mathrm{M}}}$, from 1 to $10 \mathrm{~nm}$ for $\mathrm{CNF}_{\mathrm{PP}} \mathrm{PP}_{3.8 \mathrm{M}}$ and from 100 to $500 \mathrm{~nm}$ for $\mathrm{CNF}^{\mathrm{P} P_{1.0 \mathrm{M}}}$. CNF-PP $1.0 \mathrm{M}$ proved that low acid hydrolysis molarities were not sufficient to obtain nano-sized cellulose particles, even though the variables for the mechanical treatments were improved throughout the experiment and finally led to the breakdown of the weaker interactions between the crystalline region and amorphous region of CNFs [46]. When comparing particle size distribution data, these results show that the intensity-weighted distribution and volume-weighted distribution produce considerably different particle size measurements. However, it is crucial to understand that the intensity-weighted distribution was obtained using the intensity of the light scattered by the particle fractions, whereas the volume-weighted distribution was measured using image analysis. Analysing the particle size distribution by laser diffraction yields the most accurate results [37].

\subsection{XRD Analysis}

X-ray diffraction patterns of the cellulose nanofibers were analysed to determine the influence of the molarity of acid hydrolysis on the crystallinity, where Segal's method was used to calculate 
the crystallinity index, CrI. Figure 3 displays the corresponding X-ray diffractograms obtained for

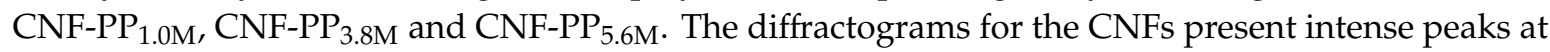
around $16.2^{\circ}, 22.6^{\circ}$, and $34.3^{\circ}$, which reflect on the crystallographic planes of (110), (200), and (004), respectively. Based on the literature, these crystallographic planes confirm that the CNF samples are in the crystal structure known as cellulose $\mathrm{I} \beta$ [25]. These results also confirm that the crystal integrity of the CNFs has been maintained through the ball milling and chemical treatment procedures [21].

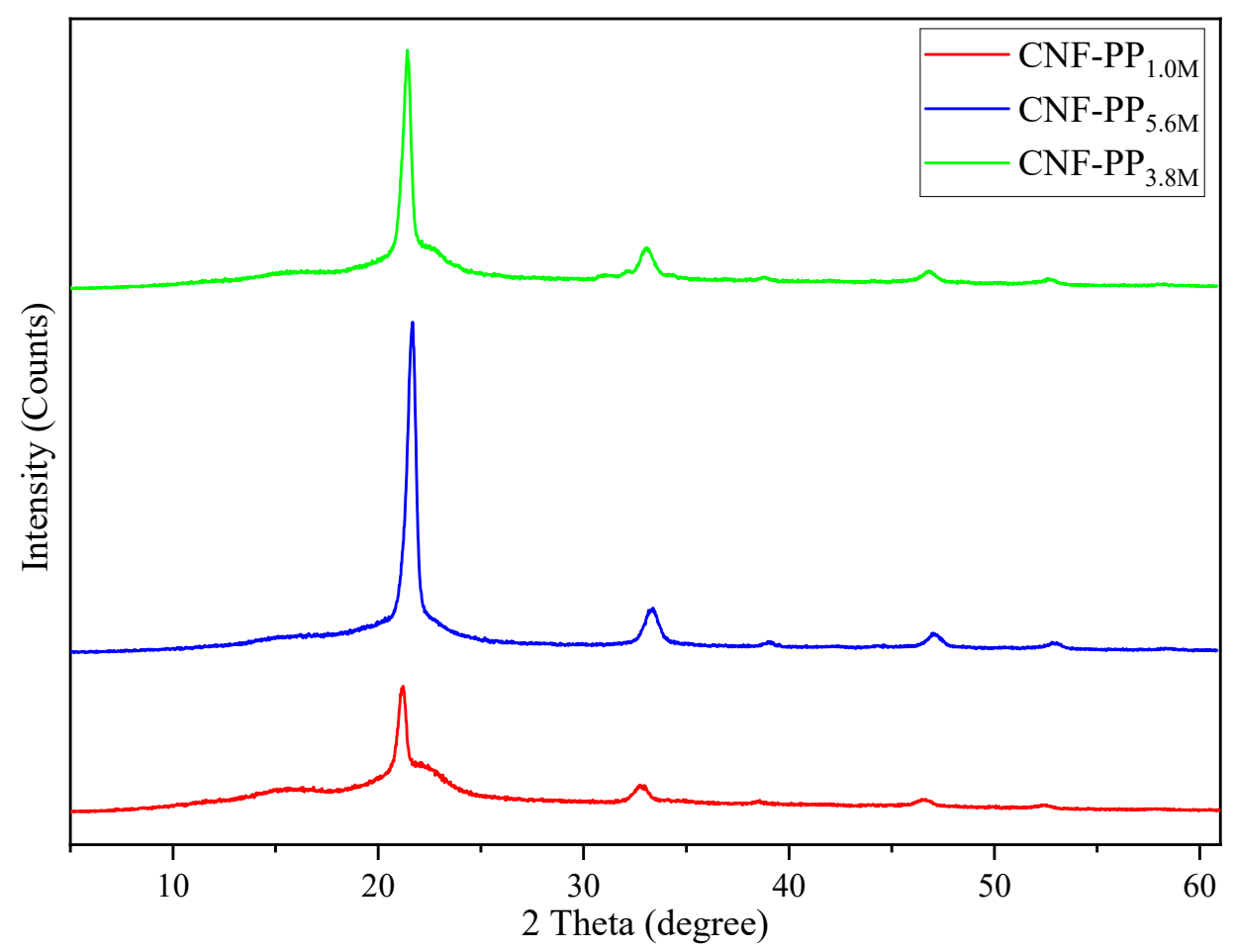

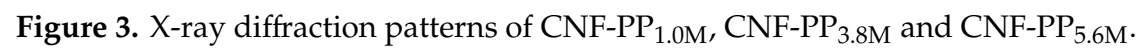

As seen in Figure 3, the crystallinity of CNFs from Napier fibers was determined at the end of the isolation process. After ball milling, significant differences on the diffraction peaks of the CNFs were

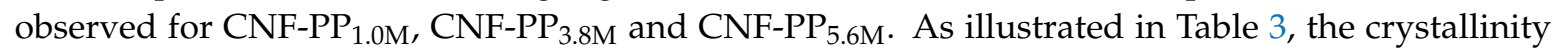
values of $\mathrm{CNF}_{-P_{1.0 \mathrm{M}}}, \mathrm{CNF} \mathrm{PP}_{3.8 \mathrm{M}}$ and $\mathrm{CNF} \mathrm{PP}_{5.6 \mathrm{M}}$ were $58.90,65.18$, and $70.67 \%$, respectively. These results evidently indicate an increase in the crystallinity index $(\mathrm{CrI})$ owing to the increase in the acid hydrolysis molarities, as stated by several authors $[25,47]$. CNF-PP $5.6 \mathrm{M}$ showed the highest degree of crystallinity at $70.67 \%$, which demonstrates sharper diffraction with an intense peak at $22.6^{\circ}$

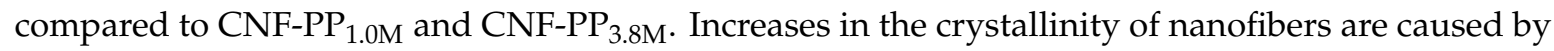
hydronium ions' $\left(\mathrm{H}_{3} \mathrm{O}^{+}\right)$charge on the reduction in the amorphous region during acid hydrolysis, leading to hydrolytic separation of the glycosidic bond of CNFs [21]. Compared to CNF-PP $1.0 \mathrm{M}$,

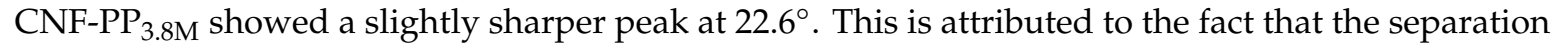
and elimination of non-cellulosic components consisting of lignin, hemicellulose, and amorphous cellulose might occur in an amorphous region of the raw fibers, which leads to a rearrangement of the crystalline order in the crystallographic plane (200) [48]. These indicate that the acid hydrolysis pre-treatment had a significant impact on the crystalline regions of the cellulose nanofibers from Napier fibers, which was supported by the FTIR results. These results illustrate that the crystallinity of cellulose nanofibers can be altered accordingly, thus these cellulose nanofibers from Napier fibers have the potential to produce nanocomposite materials with a good reinforcement capabilities for various applications. 
Table 3. XRD analysis data of $\mathrm{CNF}^{-P_{1.0 \mathrm{M}}}, \mathrm{CNF} \mathrm{PP}_{3.8 \mathrm{M}}$ and $\mathrm{CNF}^{-\mathrm{PP}_{5.6 \mathrm{M}}}$.

\begin{tabular}{|c|c|}
\hline Samples & Crystallinity Index, CrI (\%) \\
\hline CNF-PP $_{1.0 \mathrm{M}}$ & 58.90 \\
\hline $\mathrm{CNF} \mathrm{PP}_{3.8 \mathrm{M}}$ & 65.18 \\
\hline $\mathrm{CNF}^{-P}{ }_{5.6 \mathrm{M}}$ & 70.67 \\
\hline
\end{tabular}

The crystallinity displayed in this study $\left(\mathrm{CNF}-\mathrm{PP}_{5.6 \mathrm{M}}=70.67 \%\right)$ was higher than the CNFs extracted by Mahardika et al. (69.4\%) using high-shear homogenisation [46]. However, Syafri et al. showed a greater crystallinity than found in this study: $73.65 \%$ using chemical-ultrasonic treatment [49]. Nonetheless, when comparing to other studies, the present study provides a greater degree of crystallinity than those obtained by CNF from bagasse (68\%) by Kord Sofla et al. [50], CNF from empty fruit bunches of oil palm (69\%) by Jonoobi et al. [51] and CNF from banana peel (64.9\%) by Pellissari et al. [23]. It can be concluded that a higher degree of crystallinity leads to higher tensile strength, thus enhancing the mechanical properties [48] of the nanofibers as durable reinforcement fillers.

\subsection{FTIR Analysis}

The FTIR spectral features of $\mathrm{CNF}^{-P_{1.0 \mathrm{M}}}, \mathrm{CNF} \mathrm{PP}_{3.8 \mathrm{M}}$ and $\mathrm{CNF}^{-\mathrm{PP}_{5.6 \mathrm{M}}}$ under varying hydrolysis conditions are shown in Figure 4. Basically, the infrared spectral features revealed that there were no distinct changes observed among the functional groups of cellulose nanofibers of different molarity during acid hydrolysis. In addition, all the isolated nanofibers showed insignificant results on the I.R. spectra, which suggest that the isolation of CNFs at different molarities of acid hydrolysis did not influence the chemical composition of the samples. The finding concurs with the results of studies conducted on jute [7], Brazilian satin tail [52], and oil palm [53].

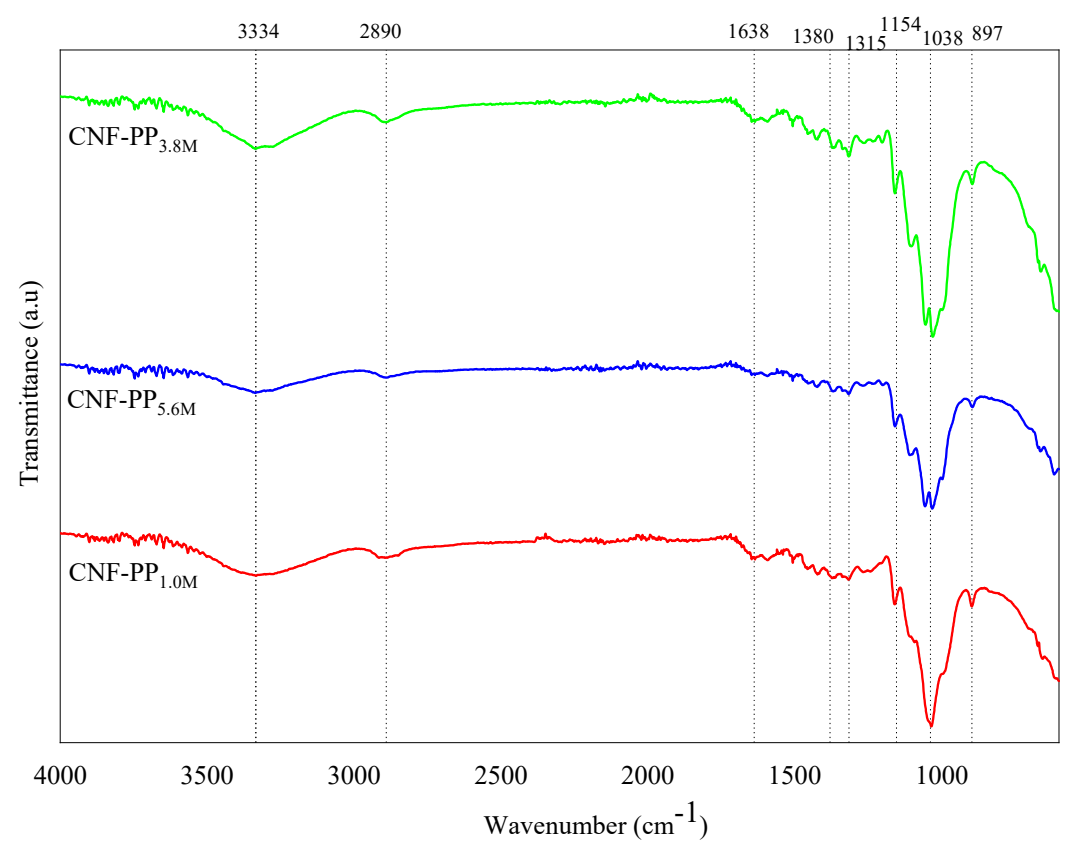

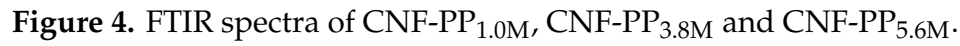

Figure 4 shows a broad band in the vicinity of $3334 \mathrm{~cm}^{-1}$ region for all samples, illustrates the presence of hydroxyl groups (O-H stretching vibration), which demonstrates the hydrophilic nature of the CNFs from Napier fibers. A more noticeable absorption peak in the spectra of the nanofibers was

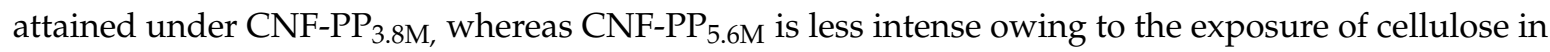
the high molarity of acid hydrolysis [52]. This is in good agreement with the observed agglomerations of CNF-PP ${ }_{5.6 \mathrm{M}}$ particles due to the presence of fewer hydroxyl groups, as mentioned in PSA analysis. 
Furthermore, the peak at $2890 \mathrm{~cm}^{-1}$ may be attributed to the $\mathrm{C}-\mathrm{H}$ symmetrical stretching of cellulose and hemicellulose, and the band observed at $1638 \mathrm{~cm}^{-1}$ is the related to the $\mathrm{O}-\mathrm{H}$ bending vibration of adsorbed water [54]. The absorbance band at $1380 \mathrm{~cm}^{-1}$ attributing to $\mathrm{S}=\mathrm{O}$ stretching, indicating that sulphate group were presence during the acid hydrolysis where sulfuric acid was utilized as the catalyst. The peaks observed in the wavelength of $1315 \mathrm{~cm}^{-1}$ in all three samples could be associated with the bending vibrations and angular deformation of the $\mathrm{C}-\mathrm{H}$ and $\mathrm{C}-\mathrm{O}$ groups, corresponding to the polysaccharide aromatic ring [41]. The peak observed at $1154 \mathrm{~cm}^{-1}$ correspond to the $\mathrm{C}-\mathrm{O}-\mathrm{C}$ stretching vibration of the glucosidic rings [42] and the peak occurring at $1038 \mathrm{~cm}^{-1}$ is related to the $\mathrm{C}-\mathrm{O}$ stretching of the pyranose ring vibration, referring to the structure of cellulose/lignin [52]. In addition, the increase in the crystallinity of the CNFs can be determined from the increase in intensity of this group [55]. Finally, the peaks at wavenumber $897 \mathrm{~cm}^{-1}$ in CNFs from Napier fibers are assigned to the $\beta$-glycosidic bonds that exist between the glucose units of cellulose/hemicellulose nanofibers. This band plays an important role in the CNF spectra, as it is proof that the cellulosic properties may not have been transformed during the acid hydrolysis process [56].

\subsection{Thermogravimetric Analysis}

Thermal decomposition and stability are essential factors to consider when proposing the use of CNFs as robust and natural fillers in reinforced composites. Figures 5 and 6 represent the thermogravimetric analysis (TGA) and derivative thermogravimetric (DTG) curves of CNF-PP $1.0 \mathrm{M}$,

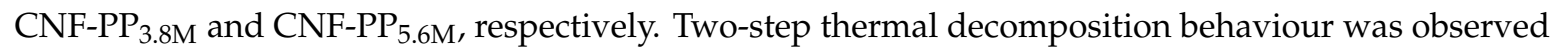
in this analysis; this is also known as a cellulose pyrolysis curve. This mechanism is strongly influenced by the chemical factors, presence of impurities, degree of crystallinity of cellulose, type of cellulose used, physical factors, temperature, heating time, and atmospheric conditions during the measurements [48]. The obtained thermal parameters of $\mathrm{CNF}^{-P_{1.0 \mathrm{M}}}, \mathrm{CNF} \mathrm{PP}_{3.8 \mathrm{M}}$ and $\mathrm{CNF}-\mathrm{PP}_{5.6 \mathrm{M}}$ from TGA and DTG analyses are summarised in Table 4.

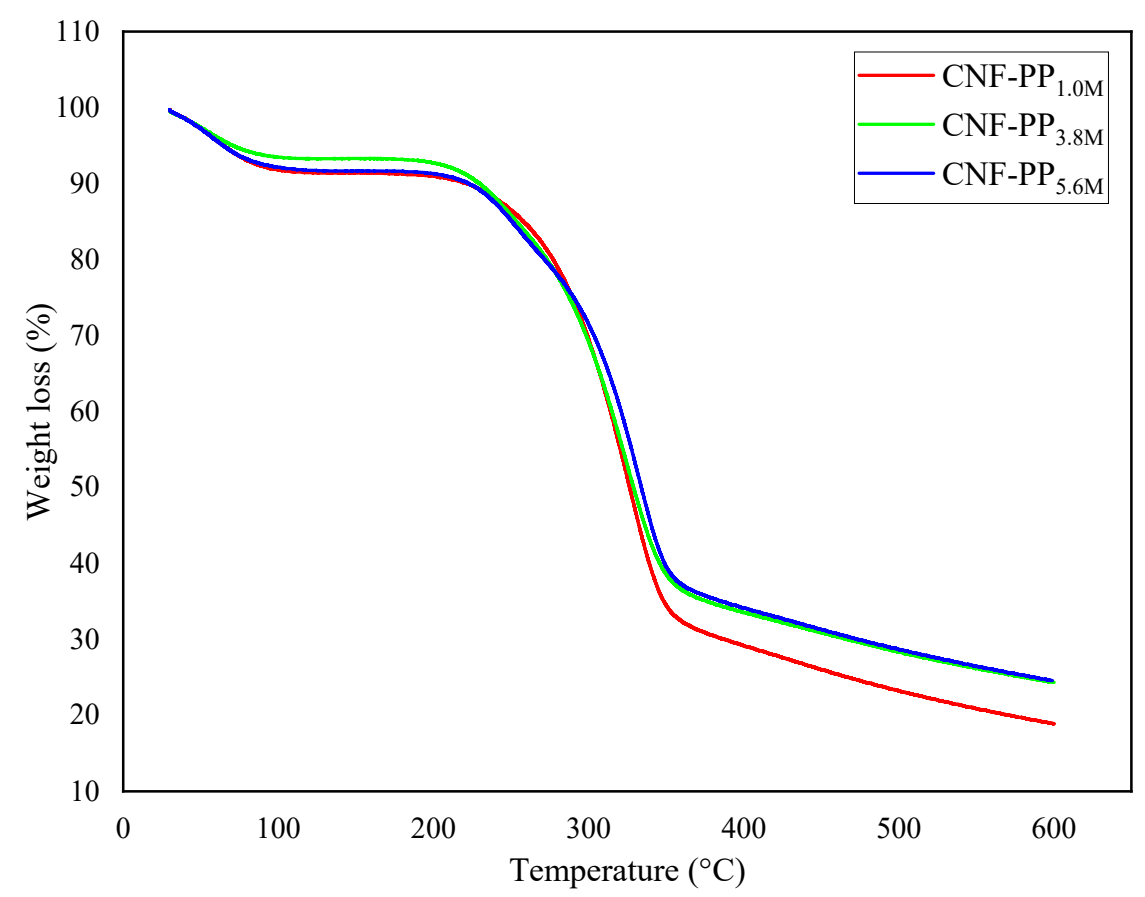

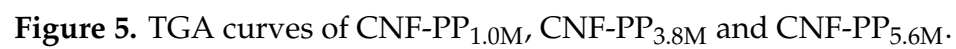




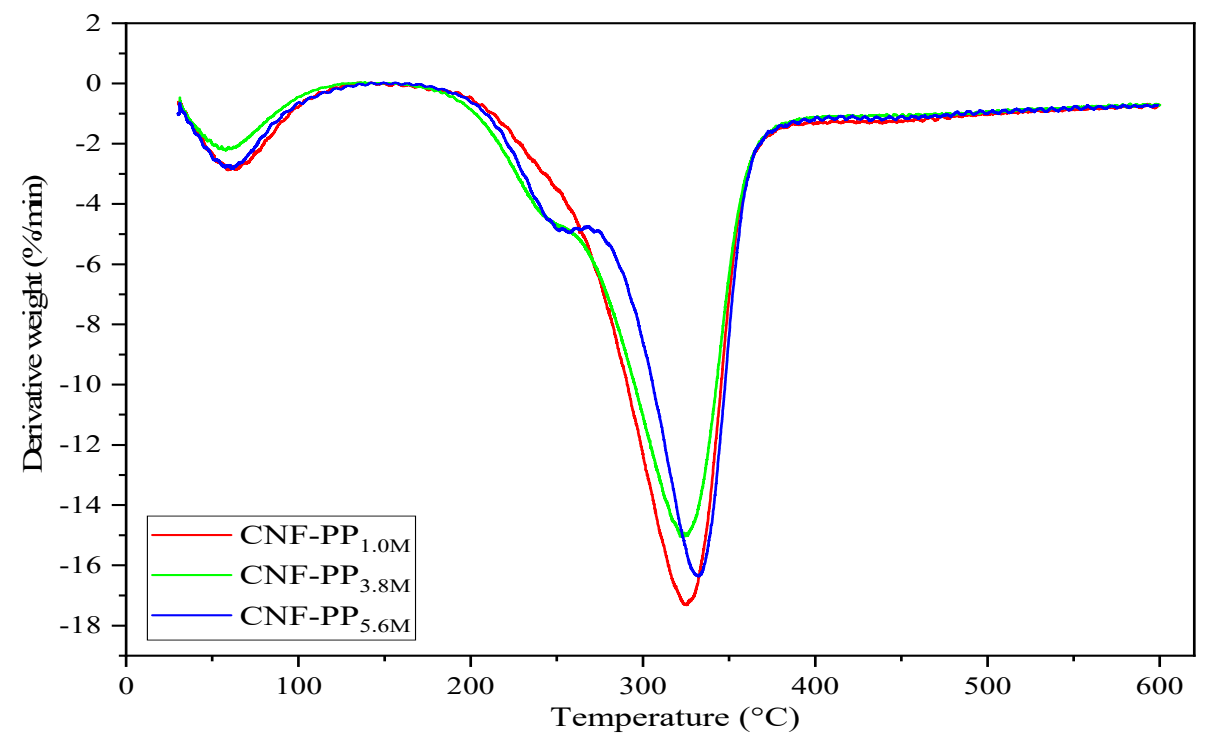

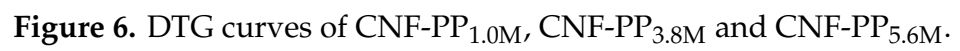

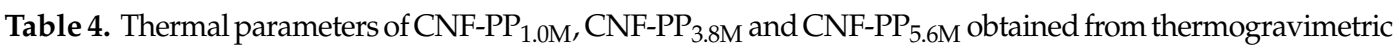
analysis (TGA) and derivative thermogravimetric (DTG) analysis.

\begin{tabular}{|c|c|c|c|c|c|c|c|}
\hline \multirow{2}{*}{ Samples } & \multicolumn{3}{|c|}{ 1st Thermal Degradation } & \multicolumn{3}{|c|}{ 2nd Thermal Degradation } & \multirow{2}{*}{$\begin{array}{l}\text { Residue at } \\
600^{\circ} \mathrm{C}(\%)\end{array}$} \\
\hline & $\mathrm{T}_{\text {onset }}\left({ }^{\circ} \mathrm{C}\right)^{\mathrm{a}}$ & $\mathrm{T}_{\text {peak }}\left({ }^{\circ} \mathrm{C}\right)^{\mathrm{b}}$ & $W_{\text {loss }}(\%)^{c}$ & $\mathrm{~T}_{\text {onset }}\left({ }^{\circ} \mathrm{C}\right)^{\mathrm{a}}$ & $\mathrm{T}_{\text {peak }}\left({ }^{\circ} \mathrm{C}\right)^{\mathrm{b}}$ & $\mathrm{W}_{\text {loss }}(\%)^{\mathrm{c}}$ & \\
\hline $\mathrm{CNF} \mathrm{PP}_{1.0 \mathrm{M}}$ & 30.23 & 61.66 & 8.18 & 269.74 & 324.90 & 48.61 & 18.91 \\
\hline $\mathrm{CNF} \mathrm{PP}_{3.8 \mathrm{M}}$ & 30.40 & 58.07 & 6.24 & 241.86 & 326.15 & 50.46 & 24.34 \\
\hline CNF-PP $_{5.6 \mathrm{M}}$ & 30.01 & 62.50 & 7.99 & 277.08 & 332.87 & 40.94 & 24.58 \\
\hline
\end{tabular}

a TGA onset temperature. ${ }^{b}$ DTG decomposition peak temperature. ${ }^{c}$ TGA weight loss.

In the initial thermal degradation stage, the samples undergo weight loss due to dehydration [57]. These occurrences were observed between 30 and $100^{\circ} \mathrm{C}$, as displayed in Figure 5. On the other hand, samples with a lower molecular weight compound consisting of a hydroxyl group at the end of the chain might get evaporated at this stage, leading to further weight loss. Subsequently, the decomposition peak temperature presented in the DTG analysis illustrates a broad peak at $61.66,58.07$ and $62.50{ }^{\circ} \mathrm{C}$

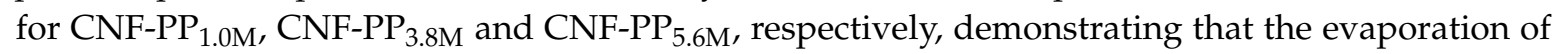
adsorbed water occurs in all CNF samples. The weight loss observed for this stage of degradation for all three samples $\mathrm{CNF}^{-P_{1.0 \mathrm{M}}}, \mathrm{CNF} \mathrm{PP}_{3.8 \mathrm{M}}$ and $\mathrm{CNF}^{\mathrm{PPP}} \mathrm{P}_{5.6 \mathrm{M}}$ was $8.17,6.24$ and 7.99\%, respectively.

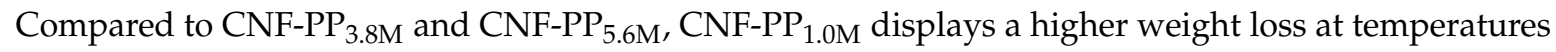

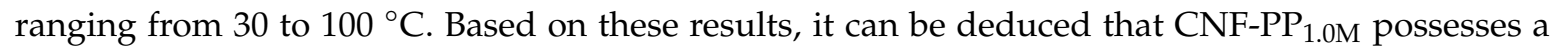

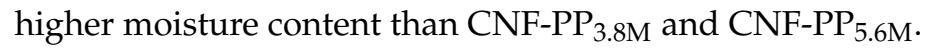

The second thermal degradation stage took place below $300^{\circ} \mathrm{C}$, between the approximate ranges of $140-280^{\circ} \mathrm{C}$, which acts as the most approachable region of the amorphous cellulose nanofibers, where there is a high content of sulfate groups. As seen in Table 4, CNF-PP ${ }_{1.0 \mathrm{M}}, \mathrm{CNF}^{\circ} \mathrm{PP}_{3.8 \mathrm{M}}$ and $\mathrm{CNF}^{\mathrm{PP}} \mathrm{5}_{5.6 \mathrm{M}}$ started to decompose at temperatures of $269.74,241.86$ and $277.08{ }^{\circ} \mathrm{C}$, respectively. According to Rahimi Kord Sofla et al., the thermal decomposition of cellulose begins in the amorphous regions and progresses to more crystalline regions [50]. These findings agree with the observations of Börjesson et al., [58] who observed that microcrystalline cellulose (MCC) with a prominent amorphous region is less resistant to high temperatures than those with ordered and compact crystalline structures. With regards to the decomposition temperature curve from the DTG analysis, as shown in Figure 6,

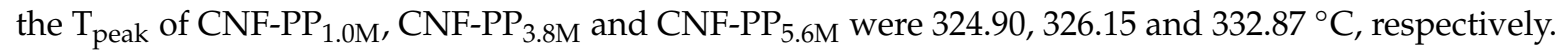
This suggested that $\mathrm{CNF}^{-P_{5.6 \mathrm{M}}}$ has a better thermal stability than $\mathrm{CNF} \mathrm{PP}_{1.0 \mathrm{M}}$ and $\mathrm{CNF}-\mathrm{PP}_{3.8 \mathrm{M}}$.

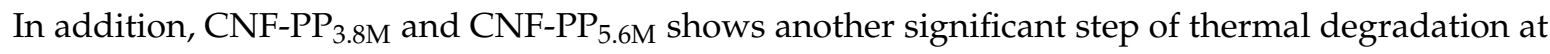
temperatures of approximately $250^{\circ} \mathrm{C}$. This step of thermal degradation can be referred to the existence 
of chemical additives which were utilized during the chemical treatments. Enhancement in the thermal stability of cellulose after undergoing chemical pre-treatment has been observed in past studies on samples such as chemically pre-treated wood fiber [59] and ramie [49].

The TGA curves illustrate that the increased molarities of acid hydrolysis lead to a decrease in the weight loss of the CNFs at temperatures above $300^{\circ} \mathrm{C}$, which is attributed to the improved thermal stability of the CNFs. However, the formation of char and low molecular weight gases occurred when active cellulose was dehydrated to produce anhydrocellulose, which consists of partially cross-linked cellulose particles [23]. The values of the char residue for $\mathrm{CNF}^{-P_{1.0 \mathrm{M}}}, \mathrm{CNF} \mathrm{PP}_{3.8 \mathrm{M}}$ and $\mathrm{CNF} \mathrm{PP}_{5.6 \mathrm{M}}$ at $600{ }^{\circ} \mathrm{C}$ were $18.91,24.34$ and $24.58 \%$, respectively. $\mathrm{CNF}_{-} \mathrm{PP}_{5.6 \mathrm{M}}$ displayed similar residue content

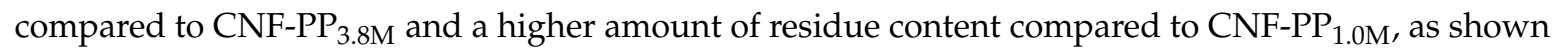
in Table 4. This is likely due to the presence of sulphate groups in the hydrolysed CNFs, where sulphate groups act as flame retardants, increasing the content of charred residues at high temperatures [57].

\section{Conclusions}

In this study, cellulose nanofibers were isolated from Napier fibers via ball milling and acid hydrolysis at different molarities. The cellulosic properties of these CNFs may not have been transformed during the chemical and mechanical treatments, which is evident from the FTIR results. Furthermore, XRD analysis indicated that the CNFs isolated by acid hydrolysis with $5.6 \mathrm{M} \mathrm{H}_{2} \mathrm{SO}_{4}$ displayed the highest crystallinity value of $70.67 \%$, indicating that it had the ability to perform well in the mechanical improvement of polymer nanocomposites. TGA revealed higher thermal stability for $\mathrm{CNF}_{-\mathrm{PP}} \mathrm{F}_{6 \mathrm{M}}$ than $\mathrm{CNF}-\mathrm{PP}_{1.0 \mathrm{M}}$ and $\mathrm{CNF} \mathrm{PP}_{3.8 \mathrm{M}}$, which was probably caused by the reduction in residual cellulose in the amorphous region of the nanofiber, as well as an increase in crystallinity during the isolation process. The microscopy studies by AFM and TEM revealed that the isolation process leads to fibrillation and the breakage of fibers into nano-sized particles, which improves the effective surface area accessible for contact. FESEM results displayed a compact structure of the nanofiber network, due to the freeze-drying effect that resulted in the agglomeration of the nanofibers. Given these findings, it can be suggested that Napier fibers can be used to produce CNFs; to be employed as reinforcing materials for the development of nanocomposites in the biomedical, automotive, and pharmaceutical industries.

Author Contributions: R.R.: Methodology, Investigation, Formal analysis, Writing-Original draft preparation, M.S.A.M.: Supervision, Funding acquisition, Writing-Review \& Editing, M.R.M.J.: Methodology, Investigation, Resources, M.J.: Writing—Review \& Editing, M.T.H.S.: Visualization, Writing-Review \& Editing, M.F.M.T.: Methodology, Investigation. All authors have read and agreed to the published version of the manuscript.

Funding: This research was funded by the Ministry of Higher Education Malaysia, through the Fundamental Research Grant Scheme; (Ref: FRGS/1/2019/TK05/UNIMAP/02/11)

Acknowledgments: The authors are grateful to i-CRiM, Universiti Kebangsaan Malaysia for providing analytical facilities. Finally, the authors would also like to acknowledge the School of Mechatronic Engineering, Universiti Malaysia Perlis (UniMAP) for the equipment and technical assistance over the course of the project. The authors would also like to thank Universiti Putra Malaysia for the financial support through the Geran Putra Berimpak (GPB-9668200), Department of Aerospace Engineering, Faculty of Engineering, Universiti Putra Malaysia and Laboratory of Biocomposite Technology, Institute of Tropical Forestry and Forest Product (INTROP), Universiti Putra Malaysia (HICOE) for the close collaboration in this research.

Conflicts of Interest: The authors declare no conflict of interest.

\section{References}

1. Reddy, K.O.; Maheswari, C.U.; Shukla, M.; Rajulu, A.V. Chemical composition and structural characterization of Napier grass fibers. Mater. Lett. 2012, 67, 35-38. [CrossRef]

2. Phanthong, P.; Reubroycharoen, P.; Hao, X.; Xu, G.; Abudula, A.; Guan, G. Nanocellulose: Extraction and application. Carbon Resour. Convers. 2018, 1, 32-43. [CrossRef]

3. Eliana, C.; Jorge, R.; Juan, P.; Luis, R. Effects of the pretreatment method on enzymatic hydrolysis and ethanol fermentability of the cellulosic fraction from elephant grass. Fuel 2014, 118, 41-47. [CrossRef] 
4. Minmunin, J.; Limpitipanich, P.; Promwungkwa, A. Delignification of Elephant Grass for Production of Cellulosic Intermediate; Elsevier: Amsterdam, The Netherlands, 2015.

5. Ridzuan, M.J.M.; Majid, A.M.S.; Afendi, M.; Aqmariah, K.S.N.; Zahri, J.M.; Gibson, A.G. Characterisation of natural cellulosic fibre from Pennisetum purpureum stem as potential reinforcement of polymer composites. Mater. Des. 2016, 89, 839-847. [CrossRef]

6. Takara, D.; Khanal, S.K. Characterizing compositional changes of Napier grass at different stages of growth for biofuel and biobased products potential. Bioresour. Technol. 2015, 188, 103-108. [CrossRef] [PubMed]

7. Baheti, V.; Abbasi, R.; Militky, J. Ball milling of jute fibre wastes to prepare nanocellulose. World J. Eng. 2012, 9, 45-50. [CrossRef]

8. De Morais Teixeira, E.; Correa, A.C.; Manzoli, A.; De Lima Leite, F.; De Ribeiro Oliveira, C.; Mattoso, L.H.C. Cellulose nanofibers from white and naturally colored cotton fibers. Cellulose 2010, 17, 595-606. [CrossRef]

9. Hu, Z.; Zhai, R.; Li, J.; Zhang, Y.; Lin, J. Preparation and Characterization of Nanofibrillated Cellulose from Bamboo Fiber via Ultrasonication Assisted by Repulsive Effect. Int. J. Polym. Sci. 2017, 2017, 1-9. [CrossRef]

10. Lin, N.; Dufresne, A. Nanocellulose in biomedicine: Current status and future prospect. Eur. Polym. J. 2014, 59, 302-325. [CrossRef]

11. Kargarzadeh, H.; Ioelovich, M.; Ahmad, I.; Thomas, S.; Dufresne, A. Methods for Extraction of Nanocellulose from Various Sources. In Handbook of Nanocellulose and Cellulose Nanocomposites; Thomas, S., Dufresne, A., Ahmad, I., Kargarzadeh, H., Eds.; Wiley-VCH Verlag GmbH \& Co. KGaA: Weinheim, Germania, 2017; pp. 1-49. [CrossRef]

12. Namvar, F.; Jawaid, M.; Tahir, P.A.S. Potential use of plants fibres and their composites for biomedical applications. Bioresources 2014, 9, 5688-5706. [CrossRef]

13. Yousefi, A.M.; Oudadesse, H.; Akbarzadeh, R.; Wers, E.; Lucas-Girot, A. Physical and biological characteristics of nanohydroxyapatite and bioactive glasses used for bone tissue engineering. Nanotechnol. Rev. 2014, 3, 527-552. [CrossRef]

14. Bigdeli, A.K.; Lyer, S.; Detsch, R.; Boccaccini, A.R.; Beier, J.P.; Kneser, U.; Horch, R.E.; Arkudas, A. Nanotechnologies in tissue engineering. Nanotechnol. Rev. 2013, 2, 411-425. [CrossRef]

15. Chirayil, C.J.; Mathew, L.; Thomas, S. Review of recent research in nano cellulose preparation from different lignocellulosic fibers. Rev. Adv. Mater. Sci. 2014, 37, 20-28.

16. Kian, L.K.; Saba, N.; Jawaid, M.; Sultan, M.T.H. A review on processing techniques of bast fibers nanocellulose and its polylactic acid (PLA) nanocomposites. Int. J. Biol. Macromol. 2019, 121, 1314-1328. [CrossRef]

17. Mishra, R.K.; Sabu, A.; Tiwari, S.K. Materials chemistry and the futurist eco-friendly applications of nanocellulose: Status and prospect. J. Saudi Chem. Soc. 2018, 22, 949-978. [CrossRef]

18. Nechyporchuk, O.; Pignon, F.; Belgacem, M.N. Morphological properties of nanofibrillated cellulose produced using wet grinding as an ultimate fibrillation process. J. Mater. Sci. 2014, 50, 531-541. [CrossRef]

19. Maciel, M.M.A.D.; Benini, K.C.C.D.C.; Voorwald, H.J.C.; Cioffi, M.O.H. Obtainment and characterization of nanocellulose from an unwoven industrial textile cotton waste: Effect of acid hydrolysis conditions. Int. J. Biol. Macromol. 2019, 126, 496-506. [CrossRef] [PubMed]

20. Chen, X.Q.; Pang, G.X.; Shen, W.H.; Tong, X.; Jia, M.Y. Preparation and characterization of the ribbon-like cellulose nanocrystals by the cellulase enzymolysis of cotton pulp fibers. Carbohydr. Polym. 2019, 207, 713-719. [CrossRef] [PubMed]

21. Kian, L.K.; Jawaid, M.; Ariffin, H.; Karim, Z. Isolation and characterization of nanocrystalline cellulose from roselle-derived microcrystalline cellulose. Int. J. Biol. Macromol. 2018, 114, 54-63. [CrossRef] [PubMed]

22. Abbasi, R.; Baheti, V. Preparation of nanocellulose from jute fiber waste. J. Text. Eng. Fash. Technol. 2018, 4, 101-104. [CrossRef]

23. Pelissari, F.M.; Menegalli, F.C. Isolation and characterization of cellulose nanofibers from banana peels. Cellulose 2014, 21, 417-432. [CrossRef]

24. Krishnan, V.N.; Ramesh, A. Synthesis and Characterization of Surface Modified Cellulose Nanofibers from Banana Peel. IOSR J. Appl. Chem. 2017, 10, 15-19. [CrossRef]

25. Xie, J.; Hse, C.Y.; De Hoop, C.F.; Hu, T.; Qi, J.; Shupe, T.F. Isolation and characterization of cellulose nanofibers from bamboo using microwave liquefaction combined with chemical treatment and ultrasonication. Carbohydr. Polym. 2016, 151, 725-734. [CrossRef] [PubMed]

26. Wu, Q.; Miao, W.; Zhang, Y.; Gao, H.; Hui, D. Mechanical properties of nanomaterials: A review. Nanotechnol. Rev. 2020, 9, 259-273. [CrossRef] 
27. Lee, H.V.; Hamid, S.B.A.; Zain, S.K. Conversion of lignocellulosic biomass to nanocellulose: Structure and chemical process. Sci. World J. 2014, 2014. [CrossRef] [PubMed]

28. Kafy, A.; Kim, H.C.; Zhai, L.; Kim, J.W.; Hai, L.V.; Kang, T.J.; Kim, J. Cellulose long fibers fabricated from cellulose nanofibers and its strong and tough characteristics. Sci. Rep. 2017, 7, 1-8. [CrossRef]

29. Feng, Y.H.; Cheng, T.Y.; Yang, W.G.; Ma, P.T.; He, H.Z.; Yin, X.C.; Yu, X.X. Characteristics and environmentally friendly extraction of cellulose nanofibrils from sugarcane bagasse. Ind. Crops Prod. 2018, 111, $285-291$. [CrossRef]

30. Zhang, Y.; Nypelo, T.; Salas, C.; Arboleda, J.; Hoeger, I.C.; Rojas, O.J. Cellulose Nanofibrils. J. Renew. Mater. 2013, 1, 195-211. [CrossRef]

31. Karim, Z.; Afrin, S. Bacterial cellulose: Preparation and Characterization. In Cellulose-Reinforced Nanofibre Composites; Jawaid, M., Boufi, S., Khalil, A.H.P.S., Eds.; Woodhead Publishing: Cambridge, UK, 2017; ISBN 9780081009659.

32. Huller, M.; Chernik, G.G.; Fokina, E.L.; Budim, N.I. Mechanical alloying in planetary mills of high accelerations. Rev. Adv. Mater. Sci. 2008, 18, 366-374.

33. Suryanarayana, C. Mechanical alloying and milling. Prog. Mater. Sci. 2001, 46, 1-184. [CrossRef]

34. Lu, S.Y.; Mao, Q.J.; Peng, Z.; Li, X.D.; Yan, J.H. Simulation of ball motion and energy transfer in a planetary ball mill. Chin. Phys. B 2012, 21, 1-9. [CrossRef]

35. Asim, M. Nanocellulose: Preparation Methods and Applications. In Cellulose-Reinforced Nanofibre Composites; Jawaid, M., Boufi, S., Khalil, A.H.P.S., Eds.; Woodhead Publishing: Cambridge, UK, 2017; pp. 261-276. ISBN 9780081009574.

36. Shak, K.P.Y.; Pang, Y.L.; Mah, S.K. Nanocellulose: Recent advances and its prospects in environmental remediation. Beilstein J. Nanotechnol. 2018, 9, 2479-2498. [CrossRef] [PubMed]

37. Leite, A.L.M.P.; Zanon, C.D.; Menegalli, F.C. Isolation and characterization of cellulose nanofibers from cassava root bagasse and peelings. Carbohydr. Polym. 2017, 157, 962-970. [CrossRef]

38. Ravindran, L.; Sreekala, M.S.; Thomas, S. Novel processing parameters for the extraction of cellulose nanofibres (CNF) from environmentally benign pineapple leaf fibres (PALF): Structure-property relationships. Int. J. Biol. Macromol. 2019, 131, 858-870. [CrossRef] [PubMed]

39. Plermjai, K.; Boonyarattanakalin, K.; Mekprasart, W.; Pavasupree, S.; Phoohinkong, W.; Pecharapa, W. Extraction and characterization of nanocellulose from sugarcane bagasse by ball-milling-assisted acid hydrolysis. AIP Conf. Proc. 2018, 2010. [CrossRef]

40. Segal, L.; Creely, J.J.; Martin, A.E.; Conrad, C.M. An Empirical Method for Estimating the Degree of Crystallinity of Native Cellulose Using the X-Ray Diffractometer. Text. Res. J. 1959, 29, 786-794. [CrossRef]

41. Jonoobi, M.; Harun, J.; Shakeri, A.; Misra, M.; Oksmand, K. Chemical composition, crystallinity, and thermal degradation of bleached and unbleached kenaf bast (Hibiscus cannabinus) pulp and nanofibers. BioResources 2009, 4, 626-639.

42. Niu, F.; Li, M.; Huang, Q.; Zhang, X.; Pan, W.; Yang, J.; Li, J. The characteristic and dispersion stability of nanocellulose produced by mixed acid hydrolysis and ultrasonic assistance. Carbohydr. Polym. 2017, 165, 197-204. [CrossRef] [PubMed]

43. Souza, A.G.D.; Kano, F.S.; Bonvent, J.J.; Rosa, D.D.S. Cellulose Nanostructures Obtained from Waste Paper Industry: A Comparison of Acid and Mechanical Isolation Methods. Mater. Res. 2017, 20, 209-214. [CrossRef]

44. Beyene, D.; Chae, M.; Dai, J.; Danumah, C.; Tosto, F.; Demesa, A.G.; Bressler, D.C. Characterization of cellulase-treated fibers and resulting cellulose nanocrystals generated through acid hydrolysis. Materials 2018, 11, 1272. [CrossRef]

45. Muhamad, M.; Hornsby, P.; Carmichael, E.; Zakaria, M.; Seok, Y.B.; Mohamed, S.; Sharma, S. Characterisation of Cellulose Nanofibres Derived from Chemical and Mechanical Treatments. MATEC Web Conf. 2019, 253, 01002. [CrossRef]

46. Mahardika, M.; Abral, H.; Kasim, A.; Arief, S.; Asrofi, M. Production of nanocellulose from pineapple leaf fibers via high-shear homogenization and ultrasonication. Fibers 2018, 6, 28. [CrossRef]

47. Chen, W.; Yu, H.; Liu, Y.; Hai, Y.; Zhang, M.; Chen, P. Isolation and characterization of cellulose nanofibers from four plant cellulose fibers using a chemical-ultrasonic process. Cellulose 2011, 18, 433-442. [CrossRef]

48. Santmartí, A.; Lee, K.Y. Crystallinity and Thermal Stability of Nanocellulose. In Production, Properties, Applications, and Case Studies; Lee, K.Y., Ed.; CRC Press: Boca Raton, FL, USA, 2018. 
49. Syafri, E.; Kasim, A.; Abral, H.; Asben, A. Cellulose nanofibers isolation and characterization from ramie using a chemical-ultrasonic treatment. J. Nat. Fibers 2019, 16, 1145-1155. [CrossRef]

50. Rahimi Kord Sofla, M.; Brown, R.J.; Tsuzuki, T.; Rainey, T.J. A comparison of cellulose nanocrystals and cellulose nanofibres extracted from bagasse using acid and ball milling methods. Adv. Nat. Sci. Nanosci. Nanotechnol. 2016, 7. [CrossRef]

51. Jonoobi, M.; Khazaeian, A.; Tahir, P.M.; Azry, S.S.; Oksman, K. Characteristics of cellulose nanofibers isolated from rubberwood and empty fruit bunches of oil palm using chemo-mechanical process. Cellulose 2011, 18, 1085-1095. [CrossRef]

52. Benini, K.C.C.D.C.; Voorwald, H.J.C.; Cioffi, M.O.H.; Rezende, M.C.; Arantes, V. Preparation of nanocellulose from Imperata brasiliensis grass using Taguchi method. Carbohydr. Polym. 2018, 192, 337-346. [CrossRef]

53. Gea, S.; Zulfahmi, Z.; Yunus, D.; Andriayani, A.; Hutapea, Y.A. The Isolation of Nanofibre Cellulose from Oil Palm Empty Fruit Bunch Via Steam Explosion and Hydrolysis with HCl 10\%. J. Phys. Conf. Ser. $2018,979$. [CrossRef]

54. Wulandari, W.T.; Rochliadi, A.; Arcana, I.M. Nanocellulose prepared by acid hydrolysis of isolated cellulose from sugarcane bagasse. IOP Conf. Ser. Mater. Sci. Eng. 2016, 107. [CrossRef]

55. Luo, X.; Wang, X. Preparation and characterization of nanocellulose fibers from $\mathrm{NaOH} /$ urea pretreatment of oil palm fibers. BioResources 2017, 12, 5826-5837. [CrossRef]

56. Chieng, B.W.; Lee, S.H.; Ibrahim, N.A.; Then, Y.Y.; Loo, Y.Y. Isolation and characterization of cellulose nanocrystals from oil palm mesocarp fiber. Polymers 2017, 9, 355. [CrossRef] [PubMed]

57. Tiwari, A.; Hihara, L.H. Thermal stability and thermokinetics studies on silicone ceramer coatings: Part 1-inert atmosphere parameters. Polym. Degrad. Stab. 2009, 94, 1754-1771. [CrossRef]

58. Borjesson, M.; Sahlin, K.; Bernin, D.; Westman, G. Increased thermal stability of nanocellulose composites by functionalization of the sulfate groups on cellulose nanocrystals with azetidinium ions. J. Appl. Polym. Sci. 2018, 135, 1-10. [CrossRef]

59. Chen, W.; Yu, H.; Liu, Y.; Chen, P.; Zhang, M.; Hai, Y. Individualization of cellulose nanofibers from wood using high-intensity ultrasonication combined with chemical pretreatments. Carbohydr. Polym. 2011, 83, 1804-1811. [CrossRef]

(C) 2020 by the authors. Licensee MDPI, Basel, Switzerland. This article is an open access article distributed under the terms and conditions of the Creative Commons Attribution (CC BY) license (http://creativecommons.org/licenses/by/4.0/). 